\title{
Highly selective PdZn/ZnO catalysts for the methanol steam reforming reaction
}

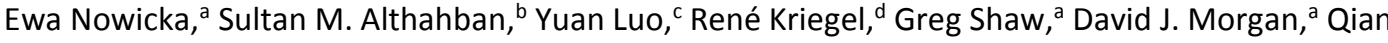 \\ $\mathrm{He},{ }^{\mathrm{a}}$ Masashi Watanabe, ${ }^{\mathrm{b}}$ Marc Armbrüster, ${ }^{\mathrm{d}}$ Christopher J. Kiely ${ }^{\mathrm{a}, \mathrm{b}}$ and Graham J. Hutchings ${ }^{* a}$ \\ One major drawback in the production of clean hydrogen from methanol is the formation of carbon monoxide which can \\ subsequently act as a poison in fuel cell applications. Here we report on $\mathrm{PdZn} / \mathrm{ZnO}$ catalysts developed for the methanol \\ steam reforming reaction which have a high selectivity towards carbon dioxide. The impregnation-based method we employ \\ for synthesising the $\mathrm{PdZn/ZnO}$ catalyst involves excess $\mathrm{Cl}^{-}$anion addition to the metal chloride precursors which results in \\ improved mixing of the metals. This subsequently leads to the formation of highly ordered PdZn alloy particles, which are \\ responsible for high catalytic selectivity. This is contrary to the situation found for $\mathrm{PdZn/ZnO}$ catalysts prepared by more \\ conventional Impregnation techniques (i.e., without the addition of excess $\mathrm{Cl}^{-}$anions), where random alloy PdZn particles \\ were generated which result in a lower selectivity to $\mathrm{CO}_{2}$.
}

\section{Introduction}

Methanol steam reforming (MSR) has gained much attention over recent years since it represents a viable method of producing pure $\mathrm{H}_{2}$ for polymer electrolyte membrane fuel cells (PEMFCs). Although this reaction is very attractive, one of the reaction by-products, $\mathrm{CO}$, is known to be a poison for $\mathrm{Pt}$ catalysts at the cathode even in very low ( $>10 \mathrm{ppm})$ concentrations. ${ }^{1}$ MSR catalysts that give high selectivity towards $\mathrm{CO}_{2}$ (i.e., low selectivity towards $\mathrm{CO}$ ) are therefore highly desired. Intermetallic PdZn catalysts have been extensively studied for this process, as they exhibit long term stability and low $\mathrm{CO}$ selectivity. ${ }^{2-4}$ It has been shown that having $\mathrm{PdZn}$ is essential as monometallic $\mathrm{Pd}$ or $\mathrm{Zn}$ catalysts only exhibited poor selectivity to $\mathrm{CO}_{2} .2,5,6$ The high selectivity of $\mathrm{PdZn}$ has been assigned to the presence of oxidized $\mathrm{Zn}$ in the near-surface region. Armbrüster et al. 7,8 investigated this phenomenon by correlating the selectivity displayed by the catalyst at different stages of the MSR reaction with highresolution transmission electron microscopy (HRTEM) images. They concluded that in-situ partial oxidation of the PdZn nanoparticles leads to small ZnO surface patches, and also inferred that the appearance of these oxidized $\mathrm{Zn}$ species is linked with high $\mathrm{CO}_{2}$ selectivity.

The formation of the $\mathrm{PdZn}$ intermetallic compounds in $\mathrm{Pd} / \mathrm{ZnO}$ catalyst materials has been investigated previously, especially in relation to varying key synthesis parameters such as the $\mathrm{Pd}: \mathrm{ZnO}$ ratio, catalyst preparation method, support

\footnotetext{
a. Cardiff Catalysis Institute, School of Chemistry, Cardiff University, Main Building, Park Place, Cardiff, CF10 3AT, UK.

b. Department of Materials Science and Engineering, Lehigh University, 5 East Packer Avenue, Bethlehem, PA 18015-3195, USA.

c. Max-Planck-Institut für Chemische Physik fester Stoffe, Nöthnitzer Strasse 40, 01187 Dresden, Germany.

d. Faculty of Natural Sciences, Institute of Chemistry, Materials for Innovative Energy Concepts, Chemnitz University of Technology, 09107 Chemnitz, Germany * Correspondence to Graham J. Hutchings, e-mail: hutch@cardiff.ac.uk Electronic Supplementary Information (ESI) available: [details of any supplementary information available should be included here]. See DOI: 10.1039/x0xx00000x
}

material and catalyst treatment conditions. ${ }^{9-12}$ It was found that the catalytic function of the material increased markedly after a reduction pre-treatment which leads to formation of the intermetallic compound. Xiong et al. ${ }^{13}$ reported that a $\mathrm{ZnO}$ supported $\mathrm{PdZn}$ catalyst which was synthesised by a hydrothermal method showed an activity increase of $53 \%$ in comparison to one prepared by impregnation using a commercial ZnO support. Chin et al. ${ }^{9}$ investigated the role of the nitrate precursor during the preparation of a $\mathrm{Pd} / \mathrm{ZnO}$ catalyst and found that the presence of nitrate anions $\left(\mathrm{NO}^{3-}\right)$ altered textural properties such as porosity and crystallinity of the $\mathrm{ZnO}$ support. In addition, it affected the extent of intermixing occurring between the $\mathrm{Zn}^{2+}$ and $\mathrm{Pd}^{2+}$ species in the subsequent heat pre-treatment step, aiding the development of $\mathrm{Pd}-\mathrm{Zn}$ interactions. ${ }^{9}$ Since the presence of anions seems to play a very important role in the formation of $\mathrm{PdZn}$ alloys, we postulated that it might be desirable to utilise them to enhance the degree of mixing between the catalyst components in the preparation step. Sankar et al. ${ }^{14}$ has previously reported the preparation of highly selective and stable $\mathrm{AuPd} / \mathrm{TiO}_{2}$ catalysts using chloride precursors along with an excess of chloride anions introduced by the addition of $\mathrm{HCl}$. Catalysts prepared using such an 'excess anion' method displayed higher stability and better re-usability in the oxidation of alcohols as compared to materials synthesised without the addition of excess $\mathrm{Cl}^{-} .{ }^{15} \mathrm{It}$ was postulated that the presence of the additional anions not only stimulates a better mixing between the metal precursors, but also limits agglomeration of the alloy particles after formation.

Here we report that by using this same 'excess anion' method of catalyst synthesis, highly selective $\mathrm{PdZn/ZnO} \mathrm{catalysts} \mathrm{can} \mathrm{be}$ prepared for the methanol steam reforming reaction. It should be noted that replacement of $\mathrm{HCl}$ with other acids (e.g., $\mathrm{H}_{2} \mathrm{SO}_{4}$, $\mathrm{H}_{3} \mathrm{PO}_{4}$ ) in the modified impregnation synthesis of the AuPd/TiO system, lowered catalyst activity and selectivity. ${ }^{14}$ Based on this prior work, we made the reasonable assumption that $\mathrm{HCl}$ would also be the optimum acid to use in the current PdZn/ZnO work. 


\section{Experimental}

\section{Catalyst Preparation}

For the preparation of the $3 \% \mathrm{PdZn} / \mathrm{ZnO}$ catalysts used in this study, $\mathrm{ZnCl}_{2}$ ( $\geq 98 \%$, Sigma Aldrich) and $\mathrm{PdCl}_{2}$ ( $\geq 99.9 \%$, Sigma Aldrich) were used as metal precursors without further purification. Additional $\mathrm{HCl}$ was introduced in the form of a 0.58 $M$ solution, prepared by the dropwise addition of $5 \mathrm{~mL}$ of concentrated $\mathrm{HCl}(37.2 \%, 12.1 \mathrm{M})$ into $95 \mathrm{~mL}$ of an $\mathrm{PdCl}_{2}$ aqueous solution ( $6 \mathrm{mg} \mathrm{Pd} / \mathrm{mL}$ ) under continuous stirring. The solution was left stirring for $16 \mathrm{~h}$ (at $500 \mathrm{rpm}$ ) at ambient temperature. For catalyst synthesis, the requisite amounts of aqueous $\mathrm{Zn}(6 \mathrm{mg} / \mathrm{mL}, 3.3 \mathrm{ml})$ and $\mathrm{Pd}$ precursor solutions $(6$ $\mathrm{mg} / \mathrm{mL}, 6.65 \mathrm{ml}$ ) were charged into a $50 \mathrm{~mL}$ round-bottom flask containing deionized water $(5 \mathrm{~mL})$; samples with $\mathrm{HCl}$ added, were designated as a modified impregnation $\left(\mathrm{M}_{\mathrm{Imp}}\right)$ catalysts, whereas those without $\mathrm{HCl}$ are termed as conventional impregnation $\left(C_{\text {Imp }}\right)$ catalysts. The content of the flask was stirred vigorously $(1000 \mathrm{rpm})$ and the temperature of the oil bath was raised from room temperature to $60^{\circ} \mathrm{C}$ over a period of $10 \mathrm{~min}$. When a temperature of $60^{\circ} \mathrm{C}$ was reached, the $\mathrm{ZnO}$ support (1.94 g, Aldrich) was added slowly over an 8-10 min period with constant stirring. The $\mathrm{pH}$ of the solution was analysed continuously using a Toledo $\mathrm{pH}$ meter. When addition of the support material was complete, the slurry was stirred at $60^{\circ} \mathrm{C}$ for an additional $15 \mathrm{~min}$ and then the temperature of the oil bath was raised to $95^{\circ} \mathrm{C}$, and the slurry was stirred overnight until all the water had evaporated leaving a dry solid. This solid powder was subsequently transferred into a mortar and pestle and was ground thoroughly. For the preparation of acid treated ZnO support materials, $6.65 \mathrm{ml}$ of $0.58 \mathrm{M}$ aqueous $\mathrm{HCl}$ was added to a round bottom flask containing $8.3 \mathrm{ml}$ water under vigorous stirring conditions. Next, $1.96 \mathrm{~g}$ of $\mathrm{ZnO}$ was added to the mixture and stirred at room temperature and the subsequent synthesis steps remained the same as for the standard preparation procedure described above. Finally, the catalyst was pre-treated in the methanol steam reforming (MSR) reactor under a steady flow of $5 \% \mathrm{H}_{2}$ in $\mathrm{Ar}$ for $4 \mathrm{~h}$ at 500 ${ }^{\circ} \mathrm{C}$ with a heating rate of $10^{\circ} \mathrm{C} / \mathrm{min}$.

\section{Methanol Steam Reforming}

Methanol steam reforming tests were carried out using powder catalyst samples $(150 \mathrm{mg}$ ) in a plug flow reactor (inner diameter $7.9 \mathrm{~mm}$, silica coated stainless steel) which was mounted inside a hot box $\left(120^{\circ} \mathrm{C}\right)$ to prevent condensation of liquids (MicroActivity, PID Eng \& Tech). The catalysts were not exposed to air after calcination and reduction treatments. The MSR feed consisted of $0.0325 \mathrm{~mL} / \mathrm{min}$ liquid $(50 \mathrm{~mol} \% \mathrm{MeOH}$ $0.0225 \mathrm{~mL} / \mathrm{min}$ (Sigma-Aldrich, $\geq 99.9 \%)$ ), 50mol\% deionized water $(0.01 \mathrm{~mL} / \mathrm{min}), 38.7 \mathrm{ml} / \mathrm{min} \mathrm{N}_{2}(99.999 \%$, Praxair) and 4.6 $\mathrm{mL} / \mathrm{min}$ He $\left(99.999 \%\right.$, Praxair). $\mathrm{N}_{2}$ was used as a carrier gas, while He was used as an inert tracer gas to calibrate the volumes of the gaseous products, since residual $\mathrm{MeOH}$ and $\mathrm{H}_{2} \mathrm{O}$ are not determined in the effluent. The gas composition in the product stream was determined every $4 \mathrm{~min}$ by gas chromatography (Varian Micro GC CP4900), which allowed for quantitative determination of $\mathrm{CO}$ with a detection limit down to $20 \mathrm{ppm}$.
Furthermore, all gaseous reactants and products were monitored by a mass spectrometer (Pfeiffer, Omnistar 300). It was not possible to directly determine the amount of unconverted $\mathrm{MeOH}$ or $\mathrm{H}_{2} \mathrm{O}$ by either $\mathrm{GC}$ and $\mathrm{MS}$ analysis, because the product gas was dried using a cooling trap and a subsequent $\mathrm{Nafion}^{\circledR}$ membrane before any gas phase analysis. For the MSR measurements, a maximum reaction temperature of $300^{\circ} \mathrm{C}$ was employed. An isothermal test of $10 \mathrm{~h}$ duration was carried out directly after a series of temperature dependent measurements including temperature changes from $150{ }^{\circ} \mathrm{C}$ to $300{ }^{\circ} \mathrm{C}$ and $175^{\circ} \mathrm{C}$ to $300{ }^{\circ} \mathrm{C}$ (using a heating and cooling rate of $\left.10^{\circ} \mathrm{C} / \mathrm{min}\right)$.

\section{Catalyst Characterization \\ BET Surface Area Measurement}

BET surface area analysis was carried out using a Quantachrome Quadrasorb evo system. A 5-point analysis was performed using $\mathrm{N}_{2}$ as the adsorbate gas. Samples were degassed in vacuum for $1 \mathrm{~h}$ at $120^{\circ} \mathrm{C}$ prior to analysis.

\section{In-situ XRD}

XRD analysis was conducted using a PANalytical X'pert Pro diffractometer employing a $\mathrm{Cu} \mathrm{K}_{\alpha} \mathrm{X}$-ray source. Typical scans were taken over a $2 \theta$ angular range between 10 and $80^{\circ}$ using $40 \mathrm{kV}$ and $40 \mathrm{~mA} \mathrm{X}$-ray source settings. Catalyst samples were heated to $500{ }^{\circ} \mathrm{C}$ under a constant flow of $5 \% \mathrm{H}_{2} / \mathrm{N}_{2}(20 \mathrm{~mL} / \mathrm{min})$ and scans were taken at $100{ }^{\circ} \mathrm{C}$ temperature intervals.

\section{$\mathrm{H}_{2}$-Temperature-Programmed Reduction (TPR)}

TPR analysis was carried out on a Thermo TPD/R/O 1100 series instrument equipped with a thermal conductivity detector (TCD). The catalyst $\left(50 \mathrm{mg}\right.$ ) was heated up to $600{ }^{\circ} \mathrm{C}$ under an atmosphere of $10 \% \mathrm{H}_{2} / \mathrm{Ar}\left(5{ }^{\circ} \mathrm{C} / \mathrm{min}\right)$ after pretreatment in $\mathrm{Ar}$ at $110^{\circ} \mathrm{C}$ for $45 \mathrm{~min}$.

\section{X-Ray Photoelectron Spectroscopy (XPS)}

XPS was performed on a Thermo Scientific K-alpha+ photoelectron spectrometer, using monochromatic $\mathrm{Al} \mathrm{K}_{\alpha}$ radiation. High resolution and survey scans were performed at pass energies of 40 and $160 \mathrm{eV}$, respectively. Charge compensation was achieved using a combination of low energy electrons and argon ions. The $\mathrm{Zn}\left(2 \mathrm{p}^{3 / 2}\right)$ signal was chosen as the calibration point, with all samples exhibiting this peak at 1021.9 $\mathrm{eV}$ and consistent with the negligible binding energy shift between $\mathrm{Zn}(0)$ and $\mathrm{Zn}(\mathrm{II})$ oxidation states. ${ }^{16}$

\section{Scanning Transmission Electron Microscopy (STEM)}

Samples for examination by STEM were prepared by dry dispersing the catalyst powder (reduced at $500^{\circ} \mathrm{C}$ ) onto a holey carbon film supported by a 300-mesh copper TEM grid. Bright field (BF) and high angle annular dark field (HAADF) STEM 
images were taken using an aberration corrected JEM ARM$200 \mathrm{CF}$ microscope operating at $200 \mathrm{kV}$. This instrument was also equipped with a JEOL Centurio silicon drift detector for X-ray energy dispersive spectroscopy (XEDS). Particle size distribution histograms were generated by analysis of representative HAADF electron micrographs using ImageJ.

\section{Results and Discussion}

In our previous work, ${ }^{14}$ we showed that $\mathrm{AuPd} / \mathrm{TiO}_{2}$ catalysts prepared by addition of excess chloride ions to the precursor metal salts produced materials with increased catalytic activity for benzyl alcohol oxidation and $\mathrm{H}_{2} \mathrm{O}_{2}$ synthesis. The additional presence of ions during the preparation step was shown to improve the mixing of the metal precursor salts to facilitate the formation of a more homogenous mixture of metal ions, thereby enabling improved dispersion during the impregnation stage. We used the same methodology for preparation of our $\mathrm{Pd}-\mathrm{Zn} / \mathrm{ZnO}$ materials, aiming to achieve more uniform PdZn alloys that might lead to higher selectivity in the MSR reaction. It should be noted that most conventional routes for preparing $\mathrm{Pd} / \mathrm{ZnO}$ catalysts for methanol steam reforming usually rely upon a single $\mathrm{Pd}\left(\mathrm{NO}_{3}\right)_{2}$ precursor. Furthermore, it was found that a highly acidic Pd precursor could affect the extent of mixing between $\mathrm{ZnO}$ and $\mathrm{Pd}^{2+} .8,9$ Since the mixing between the metallic elements should be optimised, we decided to introduce a separate $\mathrm{Zn}$ precursor $\left(\mathrm{ZnCl}_{2}\right)$ instead of just relying, as is usually the case, on interaction of deposited $\mathrm{Pd}$ with the underlying $\mathrm{ZnO}$ support. Such a method of pre-mixing $\mathrm{Pd}$ and $\mathrm{Zn}$ precursors to form intermetallic PdZn nanoparticles has been reported previously on $\mathrm{CeO}_{2} .{ }^{10}$ Similarly, $\mathrm{PdZn}$ alloys have been synthesised on supports such as $\mathrm{TiO}_{2}$ or $\mathrm{Al}_{2} \mathrm{O}_{3}$ by chemical impregnation methods. ${ }^{17}$ In addition, we compared materials prepared with ( $\mathrm{M}_{\mathrm{Imp}}$ route) and without ( $\mathrm{C}_{\mathrm{Imp}}$ route) the addition of excess $\mathrm{HCl}$ as a mixing facilitator. The resulting catalyst materials were then assessed for their efficacy in the methanol steam reforming reaction.

It should be noted that during the catalyst preparation procedure, changes in the $\mathrm{pH}$ of the precursor mixture and $\mathrm{ZnO}$ were continuously monitored. For the catalysts prepared by the standard impregnation $\mathrm{C}_{\text {Imp }}$ route, the $\mathrm{pH}$ of the $\mathrm{PdCl}_{2}, \mathrm{H}_{2} \mathrm{O}$ and $\mathrm{ZnCl}_{2}$ mixture was 1.5. In the $\mathrm{M}_{\mathrm{Imp}}$ case, the solution obtained from mixing $\mathrm{PdCl}_{2}$ (containing $0.58 \mathrm{M} \mathrm{HCl}$ ), $\mathrm{ZnCl}_{2}$ and additional $\mathrm{H}_{2} \mathrm{O}$ resulted in a $\mathrm{pH}$ value of 0.33 . After addition of $1.98 \mathrm{~g}$ of $\mathrm{ZnO}$, the $\mathrm{pH}$ value in the $\mathrm{M}_{\mathrm{Imp}}$ case rose to 6.1 , whereas for the $\mathrm{C}_{\text {Imp }}$ catalyst it increased to 6.3 . Hence, there was no significant difference in the $\mathrm{pH}$ level of the slurries prepared by the $M_{\text {Imp }}$ and $\mathrm{C}_{\mathrm{Imp}}$ methods.

For comparison of the catalytic activity of materials made by the $M_{I m p}$ and $C_{I m p}$ routes, a common nanopowder zinc oxide support was used (Aldrich, $10.8 \mathrm{~m}^{2} \mathrm{~g}^{-1}$ ) as it is well known that the surface area can influence the catalytic activity. ${ }^{13}$ First, we investigated the role of excess $\mathrm{Cl}^{-}$anions in the preparation by testing the catalysts prepared with and without $\mathrm{HCl}$. The MSR performance for each material was measured at $300{ }^{\circ} \mathrm{C}$ over a period of $10 \mathrm{~h}$ as shown in Figure 1.

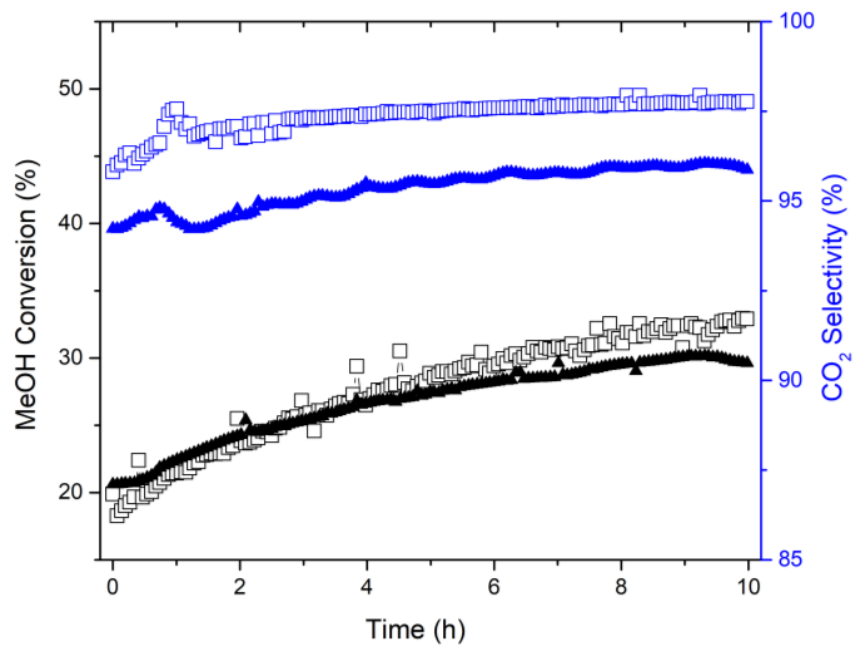

Figure 1. Methanol conversion and $\mathrm{CO}_{2}$ selectivity of freshly reduced $3 \% \mathrm{PdZn} / \mathrm{ZnO}$ MSR catalysts measured under isothermal conditions at $300{ }^{\circ} \mathrm{C}$. Key: $\mathrm{M}_{\mathrm{Imp}}$ materials prepared with $0.58 \mathrm{M} \mathrm{HCl}(\square) ; \mathrm{C}_{\mathrm{Imp}}$ material prepared without additional $\mathrm{HCl}(\boldsymbol{\Delta})$.

Both catalysts displayed similar activity levels in terms of methanol conversion, especially at the beginning of the reaction. It is worth emphasizing that the conversion increased by $15 \%$ in the case of the $M_{\operatorname{lmp}}$ catalyst over the $10 \mathrm{~h}$ duration of the test and the productivity increased from 754 to 1297 mmol $\mathrm{H}_{2}$ per mmol Pd per $\mathrm{h}$. A similar effect, although less pronounced, was also observed for the $\mathrm{C}_{\mathrm{Imp}}$ material and resulted in a conversion increase of $10 \%$ over $10 \mathrm{~h}$. These results strongly suggest that the catalyst material is undergoing some beneficial physical changes under the MSR reaction environment.

A similar general trend of improving behaviour was observed in the selectivity of the catalysts, which increased with time-on-line for both the $\mathrm{M}_{\mathrm{Imp}}$ and $\mathrm{C}_{\mathrm{Imp}} 3 \% \mathrm{Pd}-\mathrm{Zn} / \mathrm{ZnO}$ materials. However, it should be noted that the catalyst synthesized by the modified impregnation route out-performed its counterpart prepared by conventional impregnation and resulted in a significantly higher selectivity to $\mathrm{CO}_{2}$. The high selectivity to $\mathrm{CO}_{2}$ is not limited at this reaction temperature and at the $\mathrm{MeOH}$ conversion achieved, as shown by the equilibrium calculations presented in Figure S1 (Supplementary Information). The gradual improvement in catalytic performance with time-online in terms of both conversion and selectivity might be related to a structural modification of the materials under reaction conditions. For instance, Friedrich et al. ${ }^{7}$ and Heggen et al. ${ }^{8}$, using variety of in-situ microscopy techniques, have previously demonstrated that discrete $\mathrm{ZnO}$ patches can form on the supported $\mathrm{PdZn}$ intermetallic metal particles during catalyst operation. They also convincingly showed that direct oxidation of the PdZn particles occurs, as opposed to migration of $\mathrm{ZnO}$ support material over the surface of the $\mathrm{PdZn}$ particles. However, it should be noted that their catalyst originated from a monometallic $\mathrm{Pd}$ on $\mathrm{ZnO}$ material, whereas our $\mathrm{M}_{\operatorname{lmp}}$ and $\mathrm{C}_{\mathrm{Imp}}$ catalysts were prepared by co-impregnation of $\mathrm{Pd}$ and $\mathrm{Zn}$ precursors onto the $\mathrm{ZnO}$ support material.

It is interesting to compare the activity of our catalysts with other literature reports. The $\mathrm{M}_{\operatorname{lmp}} 3 \% \mathrm{Pd}-\mathrm{Zn} / \mathrm{ZnO}$ catalyst 
Table 1. Influence of support treatment on catalytic activity using bare $\mathrm{ZnO}$.

\begin{tabular}{cccc}
\hline Treatment & Conversion (\%) & Selectivity $\mathrm{CO}_{2}(\%)$ & Productivity $_{\left(\mathrm{mmol}_{\mathbf{2}} \mathrm{gcat}^{-1} \mathrm{~h}^{-1}\right)}$ \\
\hline $\mathrm{H}_{2} \mathrm{O}$ & 2 & 100 & 2.118 \\
$\mathrm{HCl}^{*}$ & 0.1 & 100 & 0.023 \\
\hline
\end{tabular}

Reaction conditions: $\mathrm{ZnO} 1 \mathrm{~g}, \mathrm{~T}=300{ }^{\circ} \mathrm{C}, \mathrm{MeOH} 0.0225 \mathrm{ml} / \mathrm{min}, \mathrm{H}_{2} \mathrm{O} 0.01 \mathrm{ml} / \mathrm{min}, \mathrm{N}_{2} 38.671 \mathrm{ml} / \mathrm{min}$. $* \mathrm{ZnO}$ washed with $0.058 \mathrm{M} \mathrm{HCl}, 2 \mathrm{~g}$ used in the reaction.

Table 2. Surface area and crystal size measurements for the fresh $\mathrm{ZnO}$ support and the $\mathrm{Mlmp}_{\mathrm{mp}}$ and $\mathrm{C}_{\mathrm{Imp}}$ derived 3\%PdZn/ZnO catalysts.

\begin{tabular}{cccc}
\hline Catalyst & Treatment & Mean ZnO crystallite size $(\mathrm{nm})$ & $\mathrm{S}_{\text {BET }}\left(\mathbf{m}^{2} \mathbf{g}^{-1}\right)$ \\
\hline $\mathrm{ZnO}$ & Fresh & 44 & 10.8 \\
& & & $\mathrm{~N} / \mathrm{A}$ \\
\multirow{2}{*}{$3 \% \mathrm{Pd}-\mathrm{Zn} / \mathrm{ZnO}(\mathrm{no} \mathrm{HCl})$} & Fresh & 46 & 10.9 \\
& Reduced & 44 & $\mathrm{~N} / \mathrm{A}$ \\
& & & 4.6 \\
\hline
\end{tabular}

showed an activity of $1297 \mathrm{mmol} \mathrm{H}_{2}$ per mmol Pd per $\mathrm{h}$, while the $C_{\text {Imp }}$ variant gave an activity of $1126 \mathrm{mmol} \mathrm{H}_{2}$ per mmol Pd per $h$. These activity levels look very promising compared to the $319 \mathrm{mmol} \mathrm{H}_{2}$ formed using a $9.2 \% \mathrm{Pd} / \mathrm{ZnO}$ catalyst as reported by Heggen et al. 8

Our primary motivation for creating excess $\mathrm{Cl}^{-}$ions via the addition of $\mathrm{HCl}$ was to ensure efficient and proper mixing of the metal precursors, however, it was also important to ascertain if these residual $\mathrm{Cl}^{-}$ions themselves affected the catalytic activity. We investigated this possibility by examining pure $\mathrm{ZnO}$ materials treated with $\mathrm{H}_{2} \mathrm{O}$ and $\mathrm{HCl}$ (see Table 1).

Lorenz et al. ${ }^{18}$ have reported that $\mathrm{ZnO}$ itself is highly selective towards $\mathrm{CO}_{2}$ when used as an MSR catalyst. Their fresh $\mathrm{ZnO}$ material gave $99.6 \%$ selectivity to $\mathrm{CO}_{2}$ and $3.6 \%$ methanol conversion ( $0.63 \mathrm{mmol} \mathrm{H}_{2} \mathrm{~g}_{\mathrm{cat}^{-1}} \mathrm{~h}^{-1}$ ). By comparing their data to that which we obtained using $\mathrm{H}_{2} \mathrm{O}$ and $\mathrm{HCl}$-treated $\mathrm{ZnO}$ for the MSR reaction (Table 1 ), it is clear that washing with $\mathrm{H}_{2} \mathrm{O}$ does not have a negative effect on catalyst selectivity or activity. However, the treatment of bare $\mathrm{ZnO}$ with $\mathrm{HCl}$ led to a decrease in the conversion suggesting that the presence of residual $\mathrm{Cl}^{-}$ ions alone could be detrimental for this reaction. Nevertheless, we show that they may play a beneficial role in the $\mathrm{PdZn} / \mathrm{ZnO}$ system, as the catalyst prepared with excess of $\mathrm{HCl}$ outperformed its counterpart prepared by the conventional impregnation method in the methanol steam reforming reaction.

\section{Catalyst Characterization}

It has also been previously reported that the surface area of the ZnO support plays an important role in determining MSR catalyst activity. ${ }^{19}$ Table 2 summarises the surface areas and mean particle size of the bare nano-powder $\mathrm{ZnO}$ as well as the $\mathrm{M}_{\mathrm{Imp}}$ and $\mathrm{C}_{\mathrm{Imp}}$ derived $3 \% \mathrm{PdZn} / \mathrm{ZnO}$ catalysts. The mean crystallite size was determined by profile fitting the FWHMs of all the $\mathrm{ZnO}$ XRD peaks using the Scherrer equation. The $\mathrm{ZnO}$ in the $M_{1 m p}$ derived catalyst was found to have a significantly lower surface area and larger mean particle size than either the $C_{\text {Imp }}$ catalyst or bare $\mathrm{ZnO}$ support material, and so might simplistically be expected to have a worse activity if surface area were the dominant parameter affecting catalytic performance. The fact that we see better catalytic performance for the $M_{\operatorname{lmp}}$ $3 \% \mathrm{PdZn} / \mathrm{ZnO}$ materials, despite it having the lowest $\mathrm{ZnO}$ surface area, means that some other factors besides surface area must be coming into play.

It might be anticipated that the modification of $\mathrm{ZnO}$ with $\mathrm{HCl}$ would lead to the undesired changes in the catalyst structure, which has led to a definite preference in the literature for preparing these $\mathrm{PdZn}$ catalysts using organic precursors. ${ }^{20}$ However, the acid treatment in our case, followed by reduction with $5 \% \mathrm{H}_{2} / \mathrm{Ar}$ for $4 \mathrm{~h}$ at $500^{\circ} \mathrm{C}$, seems to be beneficial as our $\mathrm{M}_{\mathrm{Imp}}$ 3\%PdZn/ZnO catalysts displayed higher selectivity when compared with conventionally impregnated material and previously reported $\mathrm{Pd} / \mathrm{ZnO}$ derived catalysts. ${ }^{7}$

\section{X-ray Diffraction}

The structure of both $\mathrm{M}_{\mathrm{Imp}}$ and $\mathrm{C}_{\mathrm{Imp}}$ derived catalysts during the reduction treatment were studied by in-situ XRD measurements (Figure 2). The fresh $C_{\operatorname{Imp}} \mathrm{PdZn/ZnO}$ sample prepared by conventional impregnation showed peaks consistent with the hexagonal $\mathrm{ZnO}$ phase. In contrast the samples prepared by modified Impregnation contained a significant amount of Simonkolleite (ICSD No. 77-2311) in addition to the expected $\mathrm{ZnO}$ phase. Simonkolleite is a hydrated zinc hydroxide chloride compound $\left(\mathrm{Zn}_{5} \mathrm{Cl}_{2} \mathrm{H}_{10} \mathrm{O}_{9}\right)$ which can form when $\mathrm{HCl}$ is added to $\mathrm{ZnO}$ during the $\mathrm{M}_{\operatorname{lmp}}$ synthesis procedure. This same phase was also observed in the pure $\mathrm{ZnO}$ material treated with $\mathrm{HCl}$ (Figure S2 - Supplementary Information). Interestingly, no $\mathrm{Pd}$-containing phase was observed in the XRD pattern for the fresh $\mathrm{M}_{\mathrm{Imp}} \mathrm{PdZn} / \mathrm{ZnO}$ catalyst, which might imply the formation of a Pd-containing Simonkolleite phase, which could act as a single-source precursor phase for subsequent PdZn intermetallic particles.

Heat treatment of these materials under reducing conditions (i.e., heating from $25^{\circ} \mathrm{C}$ to $500^{\circ} \mathrm{C}$ in $10 \% \mathrm{H}_{2} / \mathrm{N}_{2}$ ) led to 


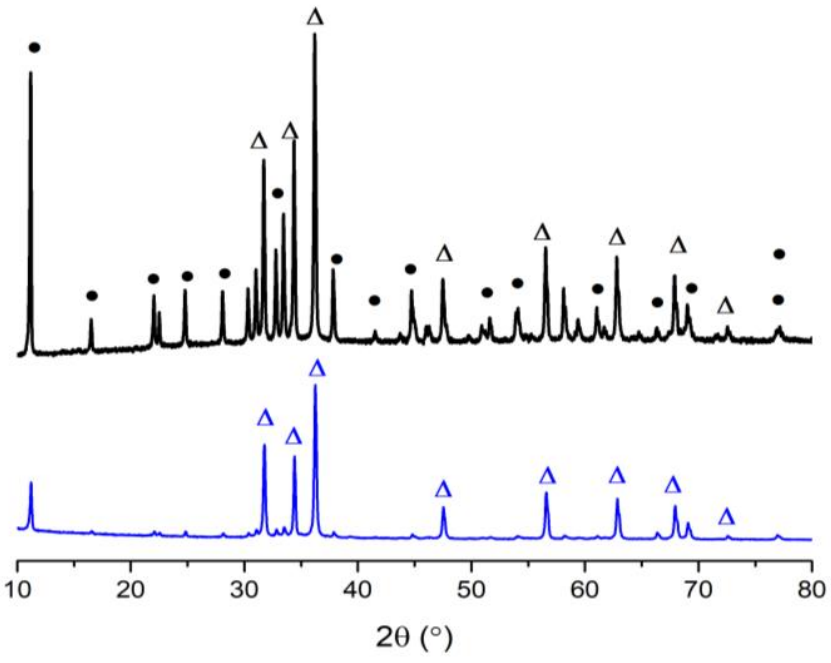

Figure 2. XRD patterns of $\mathrm{M}_{1 \mathrm{mp}}$ derived $3 \% \mathrm{Pd}-\mathrm{Zn} / \mathrm{ZnO}$ (top) and $\mathrm{C}_{\mathrm{Imp}}$ derived $3 \% \mathrm{Pd}-\mathrm{Zn} / \mathrm{ZnO}$ (bottom), in the unreduced state, analysed at $25^{\circ} \mathrm{C}$. Legend $\bullet$ symbols indicate reflections from $\mathrm{Zn}_{5} \mathrm{Cl}_{2} \mathrm{H}_{10} \mathrm{O}_{9}$, while $\Delta$ symbols are reflections from $\mathrm{ZnO}$.

significant changes in their XRD patterns (Figure 3). The reflections assigned to the Simonkolleite phase in the $M_{I m p}$ $3 \% \mathrm{PdZn} / \mathrm{ZnO}$ catalyst gradually decreased in intensity and eventually disappeared altogether. The final $\mathrm{M}_{\operatorname{lmp}} 3 \% \mathrm{PdZn} / \mathrm{ZnO}$ catalyst was found to consist of the $\mathrm{ZnO}$ support phase along with some tetragonal PdZn (ICSD 180143) alloy particles as evidenced by very weak 111 and 200-type reflections at $2 \Theta=$ $41.26^{\circ}$ and $44.04^{\circ}$ respectively. The corresponding XRD pattern for the in-situ reduced counterpart $\mathrm{C}_{\mathrm{Imp}} 3 \% \mathrm{PdZn} / \mathrm{ZnO}$ catalyst showed the expected $\mathrm{ZnO}$ reflections, but also developed weak peaks at $2 \Theta=41.42^{\circ}$ and $44.31^{\circ}$ corresponding the (111) and (200) planes of the tetragonal PdZn alloy phase. It is therefore postulated that under reducing conditions, Simonkolleite undergoes decomposition, which can then easily lead to the formation of a PdZn alloy. The formation of PdZn alloys when starting from $\mathrm{Pd} / \mathrm{ZnO}$ requires first the reduction of $\mathrm{Pd}$ and then formation of $\mathrm{PdH}_{\mathrm{x}}$. It has been reported that the strong interaction between metallic palladium or palladium hydride and the support leads to hydrogen spill-over during reduction. ${ }^{21}$ This enables the reduction of the $\mathrm{ZnO}$ in the vicinity of the Pd particles and the formation of the intermetallic $\mathrm{PdZn}$ compound at lower reduction temperatures.

XRD analysis confirmed the presence of the tetragonal PdZn phase in both the reduced $\mathrm{M}_{\mathrm{Imp}}$ and $\mathrm{C}_{\mathrm{Imp}}$ derived catalysts, but the reflections are relatively weak as the PdZn content is low $(<3 \%)$. In both materials, the PdZn alloy phase was found to form at a reduction temperature somewhere between $300^{\circ} \mathrm{C}$ and $400^{\circ} \mathrm{C}$ (Figure 4) which is in good agreement with expected literature values. ${ }^{22}$ It should also be noted that no reflections in either sample could be ascribed to the presence of monometallic Pd or Zn.

\section{Temperature Programmed Reduction}

Figure 5 shows temperature-programmed reduction (TPR) profiles for the fresh $\mathrm{M}_{\mathrm{Imp}}$ and $\mathrm{C}_{\mathrm{Imp}}$ derived 3\%PdZn/ZnO catalysts as well as for fresh and $\mathrm{HCl}$ treated bare $\mathrm{ZnO}$ nano-

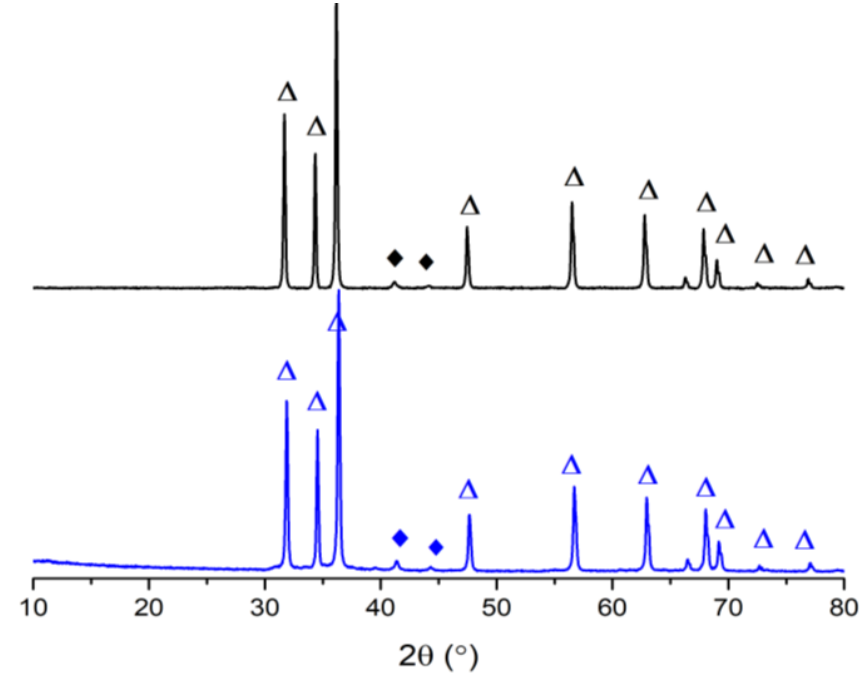

Figure 3. XRD patterns of $\mathrm{M}_{\mathrm{Imp}}$ derived 3\%PdZn/ZnO (top) and $\mathrm{C}_{\mathrm{Imp}}$ derived $3 \% \mathrm{PdZn} / \mathrm{ZnO}$ (bottom) materials after reduction in $5 \% \mathrm{H}_{2} / \mathrm{N}_{2}$ at $500^{\circ} \mathrm{C}$. Legend: symbols indicate reflections from tetragonal $\mathrm{PdZn}$, while $\Delta$ symbols are peaks from $\mathrm{ZnO}$.

powder supports. Positive peaks in a temperature range from 100 to $300^{\circ} \mathrm{C}$ were observed in the TPR traces for both the $\mathrm{M}_{\mathrm{Imp}}$ and $\mathrm{C}_{\mathrm{Imp}}$ catalysts and from the $\mathrm{HCl}$ treated $\mathrm{ZnO}$ support material. By way of contrast, the TPR trace for the untreated ZnO sample was essentially featureless. Both the $\mathrm{M}_{\operatorname{Imp}}$ and $\mathrm{C}_{\operatorname{lmp}}$ catalysts (Figures $5 \mathrm{a}$ and $\mathrm{b}$ ) show a first reduction peak just above $120^{\circ} \mathrm{C}$ (i.e., $136^{\circ} \mathrm{C}$ for $\mathrm{M}_{\operatorname{Imp}} \mathrm{PdZn} / \mathrm{ZnO}$ and $143^{\circ} \mathrm{C}$ for $\mathrm{C}_{\mathrm{Imp}}$ $\mathrm{PdZn} / \mathrm{ZnO})$. A second, well distinguished peak was observed at $185^{\circ} \mathrm{C}$ for the $\mathrm{M}_{\operatorname{Imp}} \mathrm{PdZn} / \mathrm{ZnO}$ catalyst, which was largely absent in the material prepared by the $C_{\text {Imp }}$ method. TPR analysis of the $\mathrm{HCl}$ treated $\mathrm{ZnO}$ (Figure $5 \mathrm{c}$ ), showed a comparable pattern of

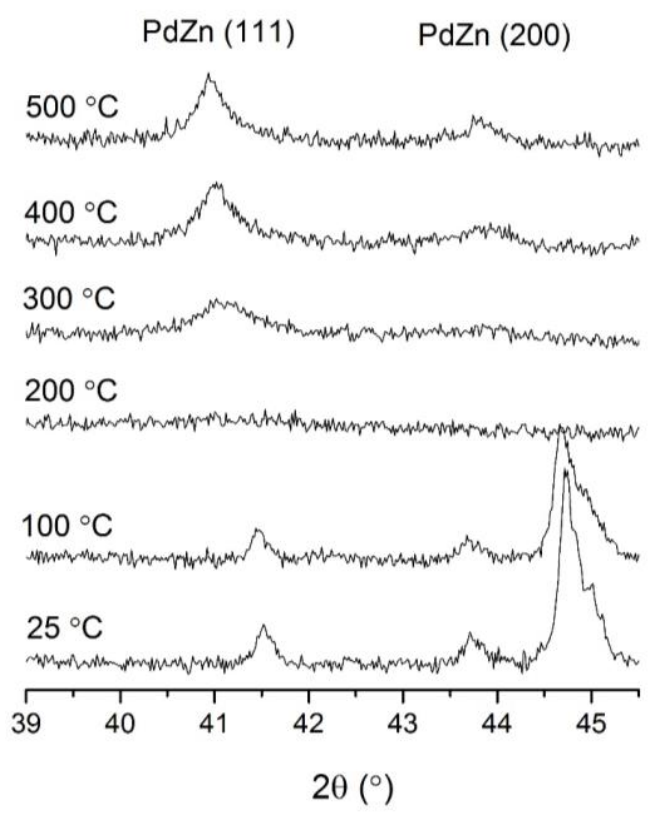

Figure 4. In-situ XRD patterns of the $\mathrm{M}_{\mathrm{Imp}}$ derived 3wt\%PdZn/ZnO catalyst: insitu analysis under reducing conditions $\left(5 \% \mathrm{H}_{2} / \mathrm{N}_{2} ; 20 \mathrm{ml} / \mathrm{min}\right)$ at several temperatures ranging between 25 and $500^{\circ} \mathrm{C}$ (Reflections at $41.43^{\circ}, 43.67^{\circ}$ and $44.69^{\circ}$ are assigned to $\mathrm{Zn}_{5} \mathrm{Cl}_{2} \mathrm{H}_{10} \mathrm{O}_{9}$ ). 


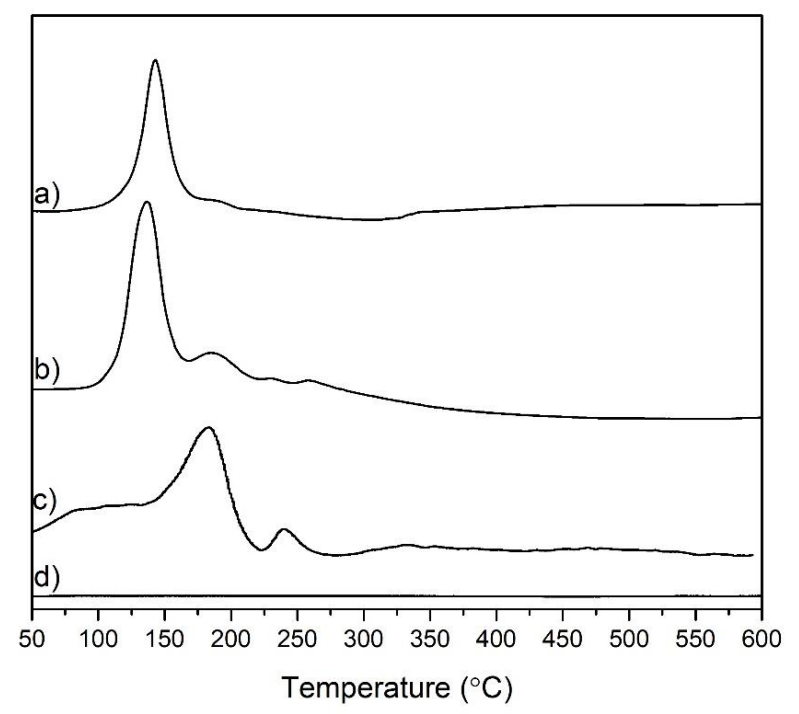

Figure 5. TPR profiles for (a) the $\mathrm{C}_{\operatorname{lmp}} 3 \% \mathrm{ZnPd} / \mathrm{ZnO}$ catalyst, (b) the $\mathrm{M}_{\operatorname{lmp}} 3 \%$ $\mathrm{ZnPd} / \mathrm{ZnO}$ catalyst (c) the $\mathrm{HCl}$ treated $\mathrm{ZnO}$ support and (d) the fresh untreated $\mathrm{ZnO}$ support.

higher temperature reduction peaks to the $M_{\operatorname{lmp}}$ catalyst, suggesting that similar species were present in these two materials. As both these samples also displayed similar XRD patterns, with many of the reflections being assigned to the Simonkolleite phase, it is therefore likely that the TPR features above $150^{\circ} \mathrm{C}$, arise from the reduction of Simonkolleite species. It is also plausible that a Pd-containing version of the

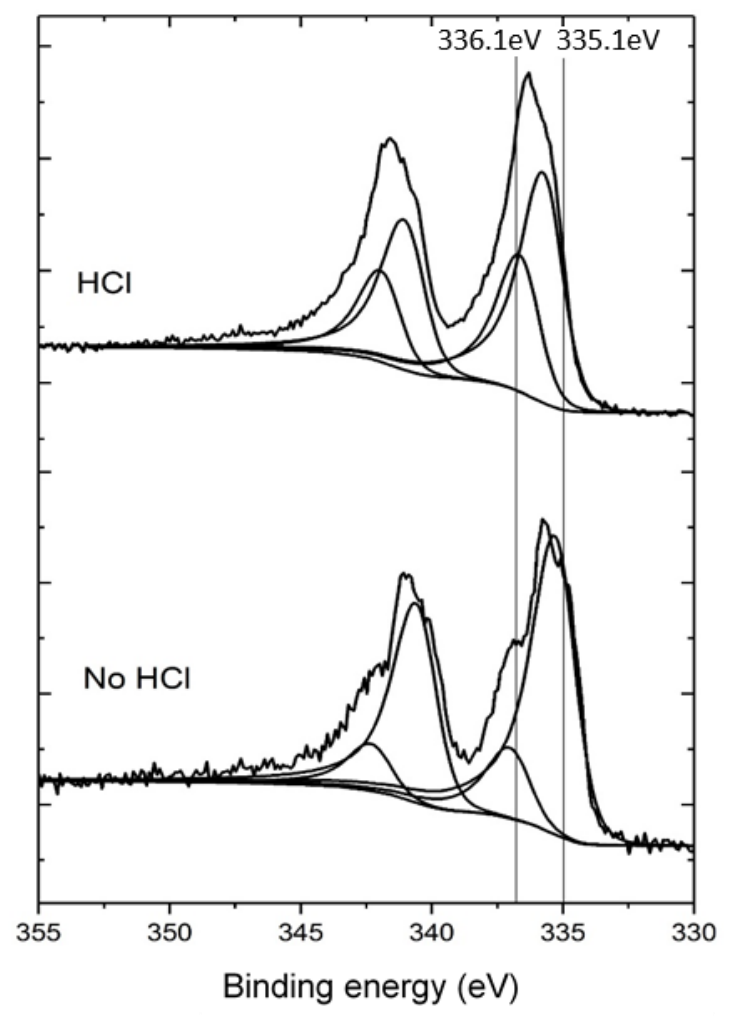

Figure 6. The $\mathrm{Pd}(3 \mathrm{~d})$ XPS spectra for reduced $\mathrm{M}_{\underline{\mathrm{mp}} \mathrm{p}}$ derived (above) and $\mathrm{C}_{\mathrm{Imp}}$ derived (below) 3\%PdZn/ZnO catalysts.
Simonkolleite phase may be present in the $\mathrm{M}_{\operatorname{lmp}} \mathrm{PdZn} / \mathrm{ZnO}$ sample which plays an important role in the subsequent formation of PdZn intermetallic compounds.

\section{XPS analysis}

XPS analysis (Table 3 ) showed that the apparent surface concentration of $\mathrm{Pd}$ for both the $\mathrm{M}_{\mathrm{Imp}}$ and $\mathrm{C}_{\mathrm{Imp}}$ catalysts decreased following reduction at $500{ }^{\circ} \mathrm{C}$. This change is concomitant with a downward shift in the binding energy of the $\mathrm{Pd}(3 \mathrm{~d})$ peaks from $337.4 \mathrm{eV}$ (characteristic of $\mathrm{Pd}-\mathrm{Cl}$ ) in the fresh samples, to ca. 336 and $335 \mathrm{eV}$ in the reduced ones (Figure 6, Figures S3 and S4 - Supplementary Information). The binding energy values of $\mathrm{Pd}\left(3 \mathrm{~d}_{5 / 2}\right)$ for $\mathrm{PdZn}$ alloys have been reported ${ }^{23,24}$ to vary from 335.1 to $336.2 \mathrm{eV}$; however, it is also accepted that alloying Pd with $\mathrm{Zn}$ increases the binding energy of the $\mathrm{Pd}\left(3 \mathrm{~d}_{5 / 2}\right)$ signal as a consequence of charge transfer and re-hybridisation. ${ }^{25}$

Table 3. XPS analysis of the $M_{I m p}$ and $C_{I m p}$ derived $3 \% P d Z n / Z n O$ catalysts in the fresh and reduced states.

\begin{tabular}{llllll}
\hline Catalyst & & \multicolumn{4}{c}{ Concentration (at \%) } \\
\cline { 3 - 6 } & & Pd & Zn & Cl & O \\
\hline \multirow{2}{*}{$C_{I m p}$} & fresh & 2.9 & 47.3 & 2.6 & 47.2 \\
$3 \% \mathrm{PdZn} / \mathrm{ZnO}$ & reduced & 2.3 & 44.0 & 3.4 & 44.5 \\
\hline $\mathrm{M}_{\operatorname{lmp}}$ & fresh & 5.4 & 34.9 & 4.7 & 48.0 \\
$3 \% \mathrm{PdZn} / \mathrm{ZnO}$ & reduced & 3.8 & 39.2 & 4.7 & 43.9 \\
\hline
\end{tabular}

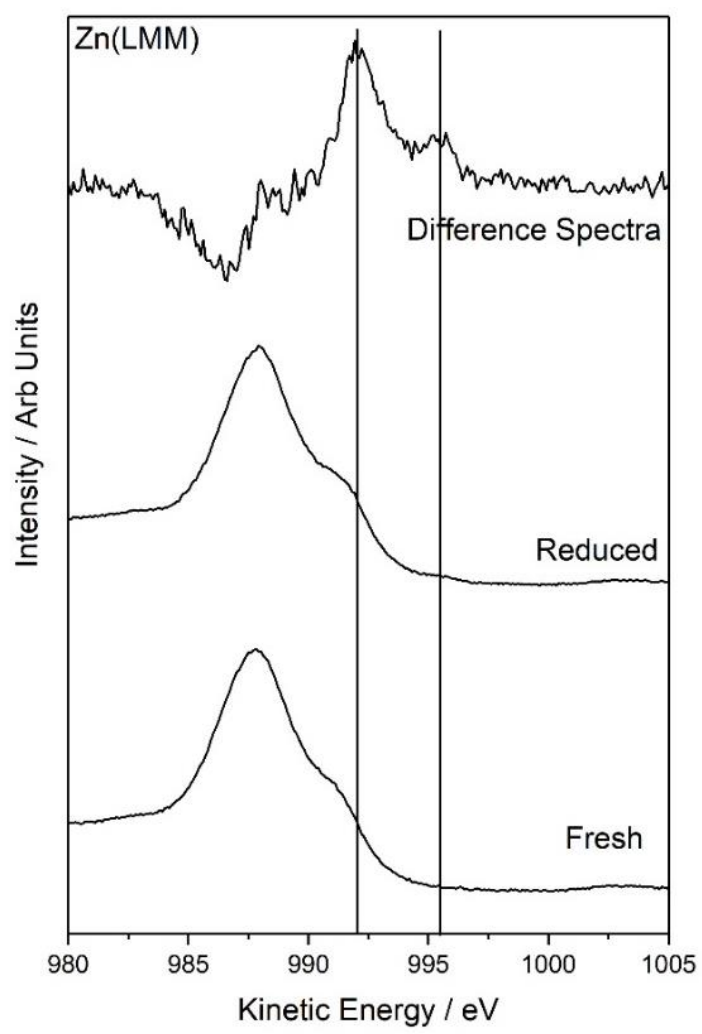

Figure 7. Zn (LMM) X-ray excited Auger electron spectra for the fresh and reduced variants of the $\mathrm{M}_{\mathrm{Imp}}$ derived $3 \% \mathrm{PdZn} / \mathrm{ZnO}$ catalyst. The difference spectrum between the fresh and reduced sample is also plotted. 
We interpret the signals at ca. 335 and $336 \mathrm{eV}$ as being either associated with discrete PdZn alloy particles of differing composition, or due to a surface enrichment of the $\mathrm{PdZn}$ nanoparticles with $\mathrm{Pd}$ caused by interaction with the atmosphere as the samples were handled ex-situ in air prior to analysis. The possibility of larger metallic Pd particles being
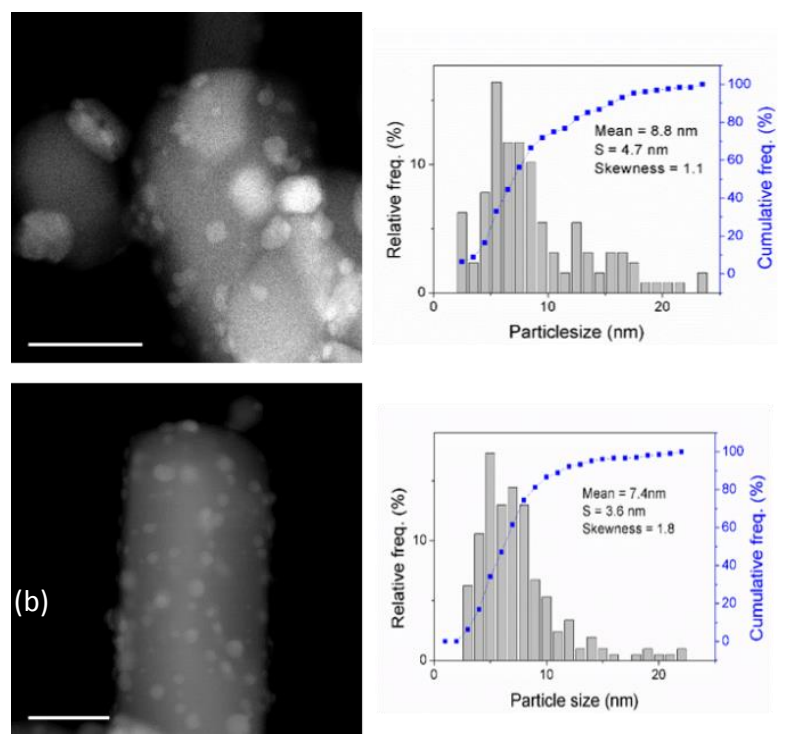

Figure 8. Representative STEM-HAADF images and the corresponding particle size distributions (PSDs) of (a) the $\mathrm{C}_{\mathrm{Imp}}$ $3 \% \mathrm{PdZn} / \mathrm{ZnO}$ catalyst and (b) the Mımp $3 \% \mathrm{PdZn} / \mathrm{ZnO}$ catalyst. present (with an expected binding energy $c a .335 \mathrm{eV}$ ) can be discounted in our $M_{\operatorname{Imp}}$ and $C_{\operatorname{Imp}}$ samples as (i) no characteristic $P d$ reflections were observed in the XRD spectra and (ii) the high selectivity of our catalysts to $\mathrm{CO}_{2}$ strongly suggests the absence of metallic Pd. ${ }^{26}$ In addition, we investigated the Zn (LMM) X-ray excited Auger emission spectra (XAES) for the fresh and reduced variants of the $\mathrm{M}_{\mathrm{Imp}}$ derived $3 \% \mathrm{PdZn} / \mathrm{ZnO}$ sample. The difference spectrum between the fresh and reduced sample is also plotted to improve the visibility of the weak shoulder feature (Figure 7). Despite no observable broadening of the $\mathrm{Zn}\left(2 \mathrm{p}_{3 / 2}\right)$ core-level, alloying of $\mathrm{Pd}$ and $\mathrm{Zn}$ is supported by the emergence of a new state in the Zn (LMM) XAES spectrum, characterised by a major peak at $992.1 \mathrm{eV}$, which corresponds to a modified Auger parameter of ca. $2014 \mathrm{eV}$ and is characteristic of metallic Zn or Zn-containing alloys. ${ }^{16,27}$

It is also clear from the XPS data shown in Table 3 that the $4 \mathrm{~h}$ reduction treatment of the catalyst in $5 \% \mathrm{H}_{2} / \mathrm{Ar}$ at $500^{\circ} \mathrm{C}$ did not result in the removal of chloride species from the $\mathrm{M}_{\operatorname{Imp}}$ and $\mathrm{C}_{\mathrm{Imp}}$ catalysts, since a detectable concentration of $\mathrm{Cl}^{-}$remained. The apparently slighter higher concentration of $\mathrm{Cl}$ present after reduction for the $\mathrm{C}_{\mathrm{Imp}}$ catalyst could be due to strong anchoring of $\mathrm{Cl}$ to the substrate, resulting in a higher apparent dispersion of $\mathrm{Cl}$ after alloying and the associated particle size changes under the reductive atmosphere. This can be supported by analysing the binding energy of $c a .199 \mathrm{eV}$, that is typical for metal- $\mathrm{Cl}$ bonds. ${ }^{16}$ Since a significant quantity of surface $\mathrm{Cl}^{-}$was detected by XPS even after reduction step, it is therefore valid to consider the possible role of residual $\mathrm{Cl}^{-}$species in the
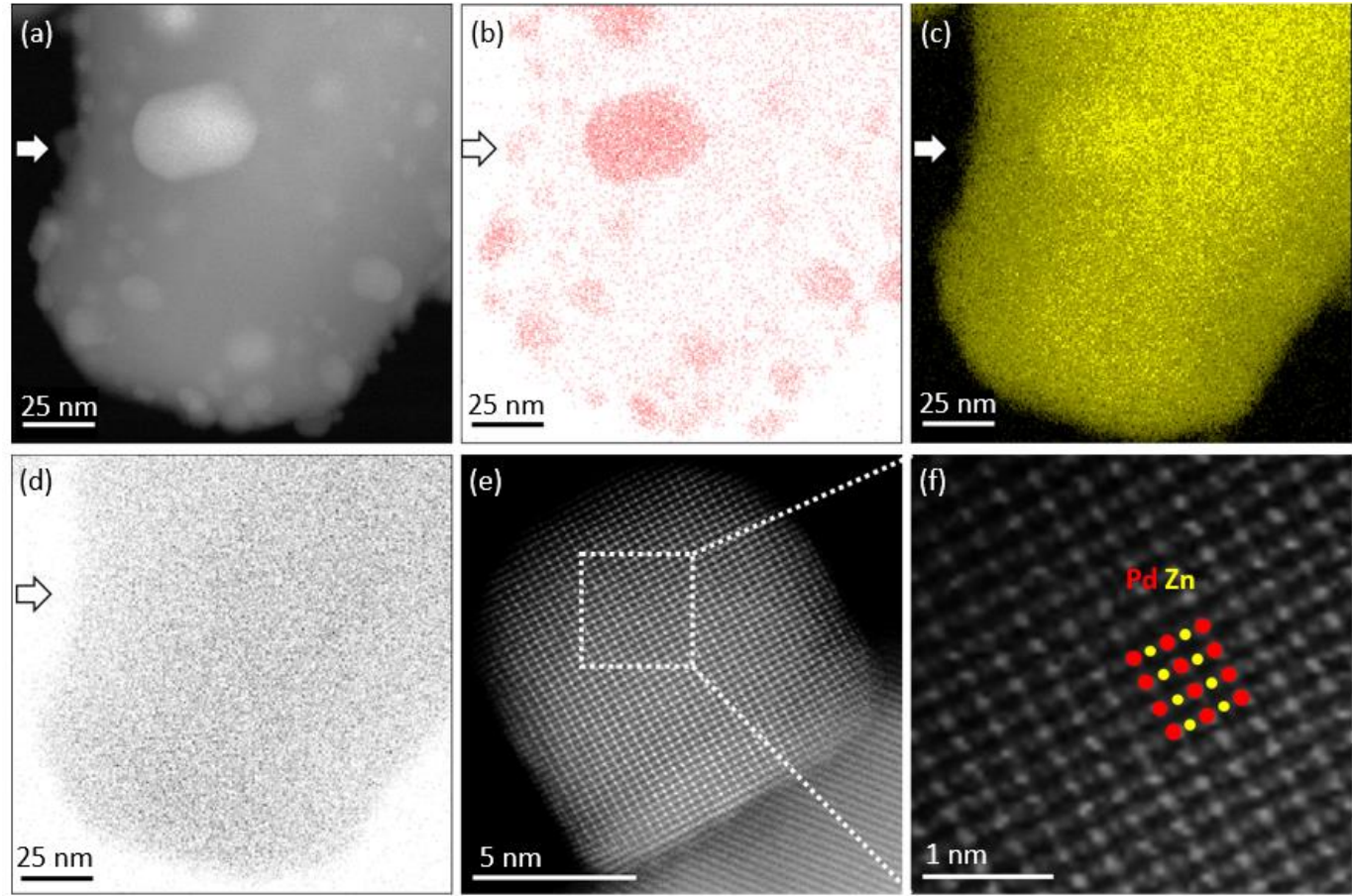

Figure 9. STEM-XEDS elemental maps and STEM-HAADF imaging of the $\mathrm{M}_{\mathrm{Imp}} 3 \% \mathrm{PdZn/ZnO}$ catalyst. A STEM-HAADF image of the catalyst is shown in (a) along with the corresponding XEDS elemental maps of (b) Pd, (c) Zn and (d) O. The intermetallic particles in profile indicated by arrows in (a-d) show the presence $\mathrm{Zn}$ and Pd but not an O signal. (e) A higher magnification STEM-HAADF image of a PdZn particle, showing characteristic L1 $1_{0}$ ordering of Pd and Zn atoms. This can be better seen in the magnified view in (f), which is overlaid with the atomic structure of PdZn (ref ICSD 180143) viewed along the [110] projection. 
methanol steam reforming reaction. As the MSR reaction was taking place at $300{ }^{\circ} \mathrm{C}$ it is very unlikely that $\mathrm{Cl}^{-}$would be removed from the catalyst surface at a temperature lower than that of the reduction step $\left(500{ }^{\circ} \mathrm{C}\right)$ during which the $\mathrm{Cl}^{-}$anions are known to remain on the surface. Also, taking into account the experimental data provided in Table 1, it is unlikely that $\mathrm{Cl}^{-}$ will have a positive effect on the catalytic activity. To address this aspect further additional STEM-XEDS studies on these catalyst samples were performed.

\section{Electron Microscopy Analysis}

Representative STEM-HAADF images of the unused $\mathrm{C}_{\operatorname{Imp}}$ and $\mathrm{M}_{\mathrm{Imp}}$ derived $3 \% \mathrm{PdZn} / \mathrm{ZnO}$ catalysts are presented in Figures $8(a)$ and 8 (b) respectively. As expected, the $\mathrm{ZnO}$ support grains, because they were of the same origin, were very similar in each case, being in the $50-200 \mathrm{~nm}$ range. The metal nanoparticles were homogeneously dispersed on the $\mathrm{ZnO}$ support grains in both cases, but the particle size distribution of each was slightly different. For the $\mathrm{M}_{\operatorname{Imp}} 3 \% \mathrm{PdZn} / \mathrm{ZnO}$ sample, the metal particles range from 3 to $22 \mathrm{~nm}$ in size, with the mean size being $\sim 7.5 \mathrm{~nm}$. The corresponding $\mathrm{C}_{\mathrm{Imp}}$ derived $3 \% \mathrm{PdZn/ZnO}$ sample displayed a slightly broader metal particle size range ( 3 to $25 \mathrm{~nm}$ ) with a higher population of the bigger particles and a larger mean metal particle size of $\sim 8.8 \mathrm{~nm}$.

Additionally, STEM-XEDS analysis was attempted to see if any significant residual $\mathrm{Cl}^{-}$is retained in our $\mathrm{M}_{\mathrm{Imp}}$ and $\mathrm{C}_{\mathrm{Imp}}$ derived PdZn/ZnO catalysts (Figures S5 and S6, Supplementary
Information). In both cases the measured XEDS intensity of the $\mathrm{Cl}$ mapping signal was quantitively in the noise level (1-3 counts only) and no identifiable $\mathrm{Cl}$ peak could be found in integrated point spectra. Therefore, the $\mathrm{Cl}$ content is below the detectability level of the XEDS technique, which is $\sim 0.5 \mathrm{wt} \%$. The discrepancy between the EDS and XPS analysis is related to the sampling depth for each technique. While the STEM-XEDS is effectively sampling the bulk of PdZn/ZnO particles, the XPS method is sampling only the first few $\mathrm{nm}$. It is therefore probable that less than 0.5 at\% $\mathrm{Cl}$ is present in total, but as it is concentrated on the catalyst surface then XPS analysis can detect its presence as noted in Table 3. It is therefore likely that the surfaces of both the $M_{I m p}$ and $C_{I m p}$ catalysts have a partial $\mathrm{Cl}^{-}$coverage, which is not removed during the reduction step.
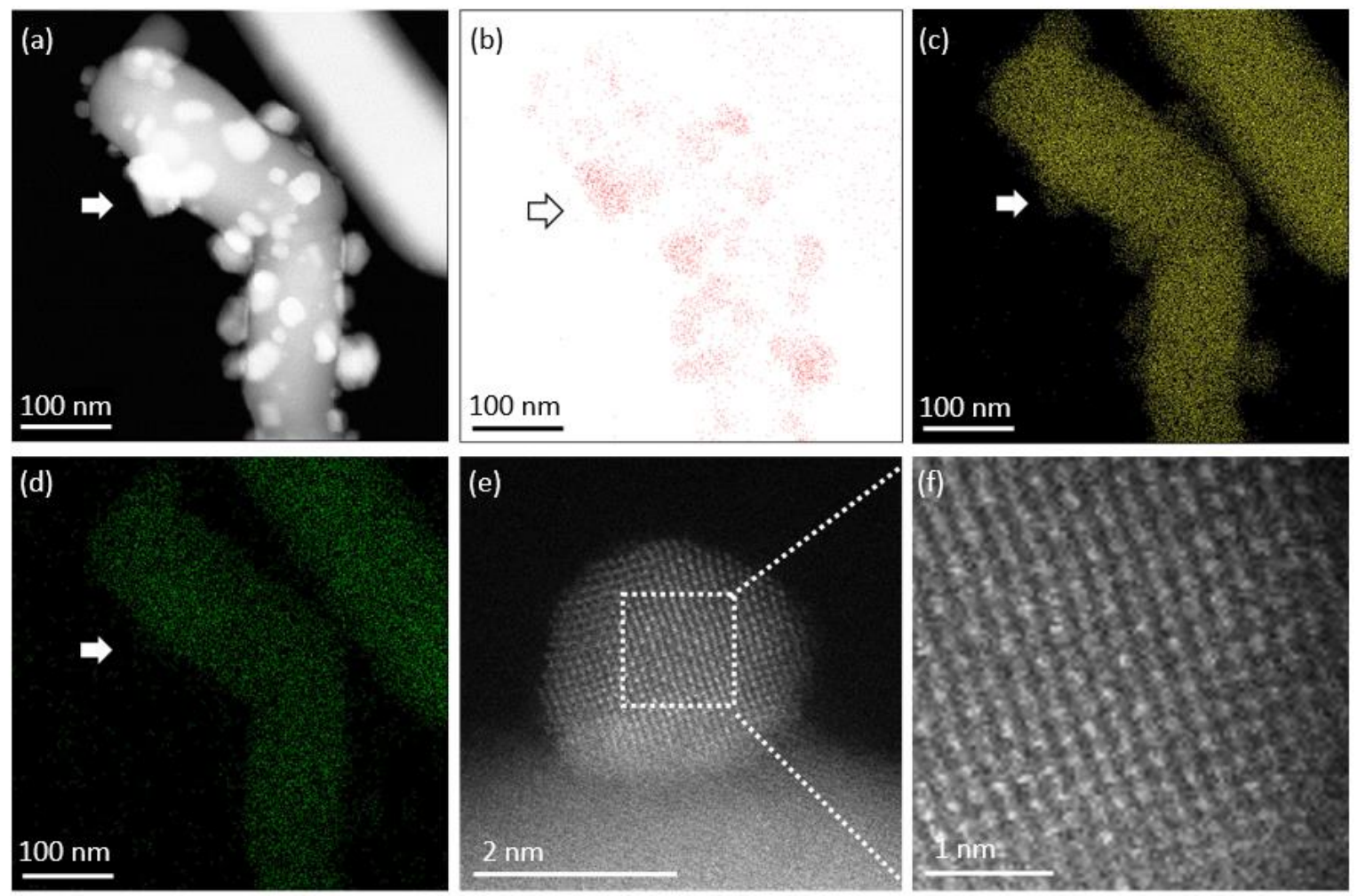

Figure 10. STEM-XEDS elemental mapping and STEM-HAADF imaging of the $\mathrm{C}_{\mathrm{Imp}} 3 \% \mathrm{PdZn/ZnO}$ catalyst. A lower magnification STEM-HAADF image of the catalyst is shown in (a) along with the corresponding XEDS elemental maps of (b) $\mathrm{Zn}$, (c) Pd and (d) O. The intermetallic particles in profile indicated by arrows in (a-d) show Zn and Pd signals but not any O. (e) A higher magnification STEM-HAADF image of a PdZn particle, showing the (L10) tetragonal PdZn phase. (f) A higher magnification HAADF image of a [001] projection of a PdZn. 

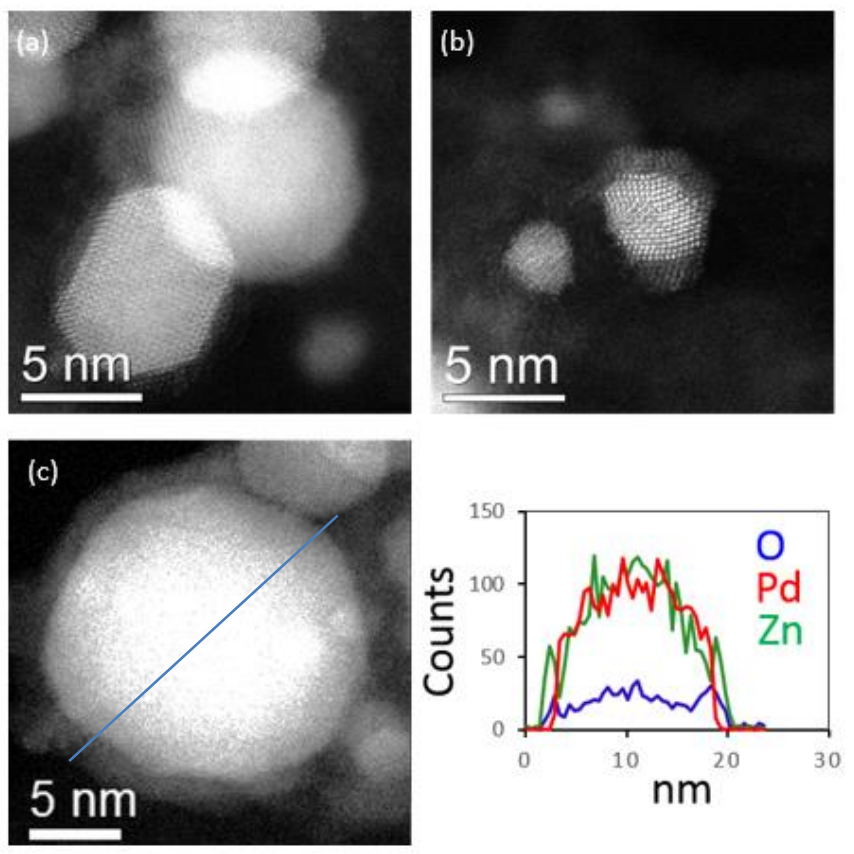

Figure 11. $(a, b, c)$ Representative HAADF images of some PdZn intermetallic particles in the $\mathrm{M}_{\mathrm{Imp}}$ derived $3 \% \mathrm{PdZn} / \mathrm{ZnO}$ catalyst after use, showing that they are no longer atomically clean, but are now decorated with a 1-2 nm thick patchy overlayer whose average mass is less than that of the PdZn particle. The XEDS line-scan in (d) was acquired along the blue line shown on the particle in (c) and shows that the surface is enriched in $\mathrm{Zn}$ and deficient in $\mathrm{Pd}$, implying the formation of a $\mathrm{ZnO}$-like surface overlayer.

The compositions of individual supported metal nanoparticles were also probed using STEM-HAADF imaging and $\mathrm{X}$-ray energy dispersive spectroscopy (XEDS), and the results are shown in Figures 9 and 10 for the $M_{1 m p}$ and $C_{I m p}$ derived $3 \% \mathrm{PdZn} / \mathrm{ZnO}$ catalysts, respectively. The metal particles examined on both catalysts were all found to be PdZn alloys, as evidenced by the presence of both Pd and $\mathrm{Zn}$ signals in XEDS maps of particles oriented in profile view at the edge of the $\mathrm{ZnO}$ support, (which are highlighted with arrows in Figures 9 (a-d) and Figures 10 (a-d)). Higher magnification atomic resolution STEM-HAADF images of representative PdZn particles for the two catalysts are shown in Figures $9(e, f)$ and $10(e, f)$. Measurement of lattice spacings and interplanar angles confirmed the supported alloy particles in both cases to have a tetragonal structure consistent with PdZn (ICSD 180143) which is known to exist for alloy compositions containing between 38 and 50 at\% $\mathrm{Zn}$. In the $\mathrm{M}_{\mathrm{Imp}}$ derived catalysts the $\mathrm{PdZn}$ particles when viewed along certain crystal projections (e.g., [010] and [110]) showed strong and distinct periodic mass contrast in HAADF images that is consistent with $\mathrm{L}_{1}$ type ordering of $\mathrm{Pd}$ and $\mathrm{Zn}$ atoms on alternate atomic columns. To illustrate this atomic ordering more clearly, Figure $9(f)$ shows a magnified [110] HAADF projection view of the atomic structure in Figure 9(e) with the theoretical atomic structure projection of $L 1_{0}$ type $\mathrm{PdZn}$ superimposed on top of the experimental image. A distinct difference noted in the $\mathrm{C}_{\mathrm{Imp}}$ derived $3 \mathrm{wt} \% \mathrm{PdZn} / \mathrm{ZnO}$ catalysts was that the vast majority of the PdZn alloy particles, while showing a tetragonal structure, did not show the high degree of ordering on the Pd and $\mathrm{Zn}$ sub-lattices that was found for the $M_{I m p}$ derived materials (Figures $10(e, f)$ ).

The $\mathrm{M}_{\mathrm{Imp}}$ 3wt\%PdZn/ZnO material was also examined after $10 \mathrm{~h}$ use as an MSR catalyst. As shown in Figure 11, the catalyst structure was significantly modified during the activation and use process. The supported PdZn alloy particles were no longer atomically clean but became decorated with a 1-2 nm thick patchy overlayer whose average mass is less than that of the underlying PdZn particle (Figures 11(a-c)). The XEDS line-scan shown in Figure 11 (d) was acquired along the blue line indicated on the particle in Figure 11 (c) and shows that the surface is enriched in $\mathrm{Zn}$ and deficient in Pd, implying the formation of a $\mathrm{ZnO}$-like surface overlayer. It is unclear if this overlayer originates from (i) preferential $\mathrm{Zn}$ oxidation in the $\mathrm{PdZn}$ particle surface or (ii) ZnO migrating from the support over the $\mathrm{PdZn}$ particle via a strong metal support interaction (SMSI) effect. The existence of $\mathrm{ZnO}$ islands on the $\mathrm{PdZn}$ particle surface is however entirely consistent with previous reports from Armbruster et al who associated this morphology with fully active catalysts. ${ }^{7,} 8$ The time needed to develop this overlayer also seems to correlate with the induction period required for this $\mathrm{PdZn} / \mathrm{ZnO}$ catalyst to reach its full activity.

\section{Conclusions}

A 3\% PdZn/ZnO catalyst has been synthesized using a modified impregnation $\left(\mathrm{M}_{\mathrm{Imp}}\right)$ technique in which excess $\mathrm{Cl}^{-}$ions were introduced along with the metal precursor salts. As a result, a highly selective catalyst for the methanol steam reforming reaction was obtained. The origin of the high selectivity to $\mathrm{CO}_{2}$ lies in the lack of monometallic $\mathrm{Pd}$ and the efficient formation of homogeneously distributed and structurally ordered PdZn intermetallic particles. This desirable nanostructure was achieved by the efficient mixing between the metal chloride precursors occurring as a result of $\mathrm{HCl}$ addition and perhaps the formation of a mixed cation compound resembling a Pdcontaining Simonkolleite phase. This is further supported by comparisons with the corresponding catalyst prepared by a more conventional impregnation method which was comprised of larger random alloy $\mathrm{PdZn}$ particles and exhibited a lower selectivity towards $\mathrm{CO}_{2}$. It is believed that the main contributor to improvement of catalytic activity observed for both the $M_{1 m p}$ and $C_{I m p}$ materials with time-on-line is the formation of nanoscale $\mathrm{ZnO}$ islands on the surface of $\mathrm{PdZn}$ particles. However, the role of residual $\mathrm{Cl}^{-}$present in the catalyst and its influence on catalytic activity still needs further investigation and should not be excluded from consideration.

\section{Conflicts of interest}

There are no conflicts to declare.

\section{Acknowledgements}

We thank the European Research Council grant ERC-2011-ADG, grant agreement no. 291319, acronym “AFTER-THE-GOLDRUSH. 
The COST Action CM0904 is also gratefully acknowledged. CJK gratefully acknowledges funding from the National Science Foundation Major Research Instrumentation program (GR\# MRI/DMR-1040229). SMA thanks the Saudi Arabian government for his PhD scholarship.

\section{Notes and references}

1. H. P. Dhar, L. G. Christner and A. K. Kush, Journal of the Electrochemical Society, 1987, 134, 3021-3026.

2. N. Iwasa, S. Masuda, N. Ogawa and N. Takezawa, Applied Catalysis A-General, 1995, 125, 145-157.

3. H. Zhang, J. M. Sun, V. L. Dagle, B. Halevi, A. K. Datye and Y. Wang, ACS Catalysis, 2014, 4, 2379-2386.

4. M. Armbruster, M. Behrens, K. Fottinger, M. Friedrich, E. Gaudry, S. K. Matam and H. R. Sharma, Catalysis ReviewsScience and Engineering, 2013, 55, 289-367.

5. N. Iwasa, S. Masuda and N. Takezawa, Reaction Kinetics and Catalysis Letters, 1995, 55, 349-353.

6. N. Iwasa, T. Mayanagi, N. Ogawa, K. Sakata and N. Takezawa, Catalysis Letters, 1998, 54, 119-123.

7. M. Friedrich, S. Penner, M. Heggen and M. Armbruster, Angewandte Chemie-International Edition, 2013, 52, 4389 4392.

8. M. Heggen, S. Penner, M. Friedrich, R. E. Dunin-Borkowski and M. Armbruster, Journal of Physical Chemistry C, 2016, 120, 10460-10465.

9. Y. H. Chin, Y. Wang, R. A. Dagle and X. H. S. Li, Fuel Processing Technology, 2003, 83, 193-201.

10. N. Iwasa, T. Mayanagi, W. Nomura, M. Arai and N. Takezawa, Applied Catalysis A-General, 2003, 248, 153 160.

11. N. Iwasa, S. Kudo, H. Takahashi, S. Masuda and N. Takezawa, Catalysis Letters, 1993, 19, 211-216.

12. T. Conant, A. M. Karim, V. Lebarbier, Y. Wang, F. Girgsdies, R. Schlogl and A. Datye, Journal of Catalysis, 2008, 257, 64 70.

13. G. Xiong, L. Luo, C. Li and X. Yang, Energy \& Fuels, 2009, 23, 1342-1346.

14. M. Sankar, Q. He, M. Morad, J. Pritchard, S. J. Freakley, J. K. Edwards, S. H. Taylor, D. J. Morgan, A. F. Carley, D. W. Knight, C. J. Kiely and G. J. Hutchings, ACS Nano, 2012, 6, 6600-6613.

15. M. Morad, M. Sankar, E. H. Cao, E. Nowicka, T. E. Davies, P. J. Miedziak, D. J. Morgan, D. W. Knight, D. Bethell, A. Gavriilidis and G. J. Hutchings, Catalysis Science \& Technology, 2014, 4, 3120-3128.

16. H. Bahruji, J. R. Esquius, M. Bowker, G. Hutchings, R. D. Armstrong, W. Jones, Topics in Catalysis, 2018, 61, 144153.

17. NIST X-ray Photoelectron Spectroscopy Database, Version 4.1 in National Institute of Standards and Technology, Gaithersburg, 2012.

18. H. Lorenz, M. Friedrich, M. Armbruster, B. Klotzer and S. Penner, Journal of Catalysis, 2013, 297, 151-154.

19. G. W. Xiong, L. T. Luo, C. Q. Li and X. M. Yang, Energy \& Fuels, 2009, 23, 1342-1346.

20. A. M. Karim, T. Conant and A. K. Datye, Physical Chemistry Chemical Physics, 2008, 10, 5584-5590.

21. N. Iwasa, N. Takezawa, Topics in Catalysis, 2003, 22, 215224.
22. H. Nowotny and H. Bittner, Monatshefte Fur Chemie, 1950, 81, 679-680.

23. C. Rameshan, C. Weilach, W. Stadlmayr, S. Penner, H. Lorenz, M. Havecker, R. Blume, T. Rocha, D. Teschner, A. Knop-Gericke, R. Schlogl, D. Zemlyanov, N. Memmel, G. Rupprechter and B. Klotzer, Journal of Catalysis, 2010, 276, 101-113.

24. M. Lenarda, E. Moretti, L. Storaro, P. Patrono, F. Pinzari, E. Rodriguez-Castellon, A. Jimenez-Lopez, G. Busca, E. Finocchio, T. Montanari and R. Frattini, Applied Catalysis AGeneral, 2006, 312, 220-228.

25. J. A. Rodriguez, Journal of Physical Chemistry, 1994, 98, 5758-5764.

H. Bahruji, M. Bowker, G. Hutchings, N. Dimitratos, P. Wells, E. Gibson, W. Jones, C. Brookes, D. Morgan and G. Lalev, Journal of Catalysis, 2016, 343, 133-146.

27. F. Cocco, B. Elsener, M. Fantauzzi, D. Atzei and A. Rossi, RSC Advances, 2016, 6, 31277-31289. 